\title{
Undercoordinated indium as an intrinsic electron-trap center in amorphous $\operatorname{InGaZnO}_{4}$
}

\author{
Ho-Hyun Nahm ${ }^{1,2}$ and Yong-Sung $\mathrm{Kim}^{3,4}$ \\ Undercoordinated indium $\left(\mathrm{In}^{*}\right)$ is found to be an intrinsic defect that acts as a strong electron trap in amorphous $\operatorname{InGaZnO}_{4}$. \\ Conduction electrons couple with the under-coordinated $\ln ^{*}$ via Coulomb attraction, which is the driving force for the formation \\ of an $\ln ^{*}-\mathrm{M}(\mathrm{M}=\ln , \mathrm{Ga}$, or $\mathrm{Zn})$ bond. The new structure is stable in the electron-trapped (2-) charge state, and we designate it \\ as an intrinsic $\left(\operatorname{In}^{*}-\mathrm{M}\right)^{2-}$ center in amorphous $\operatorname{InGaZnO} \mathrm{H}_{4}$. The $\left(\operatorname{In}^{*}-\mathrm{M}\right)^{2-}$ centers are preferentially formed in heavily $n$-doped \\ samples, resulting in a doping limit. They are also formed by electrical/optical stresses, which generate excited electrons, \\ resulting in a metastable change in their electrical properties.
}

NPG Asia Materials (2014) 6, e143; doi:10.1038/am.2014.103; published online 14 November 2014

\section{INTRODUCTION}

The identification of charge-trapping defects on the atomic scale has been achieved in crystalline semiconductors. A donor can capture carrier electrons with large lattice relaxations, forming a DX (donor (D) deactivated $(\mathrm{X})$ ) center $^{1-5}$ whereas an acceptor traps holes, forming an AX (acceptor (A) deactivated (X)) center. ${ }^{5-7}$ However, in amorphous semiconductors, even though many charge-trapping phenomena that can modify electronic device characteristics ${ }^{8}$ and be applied to nonvolatile memory devices ${ }^{9}$ have been observed, the atomic and electronic structures of the charge-trapping defects lack clear understanding.

Amorphous oxide semiconductors seriously suffer from chargetrapping events. ${ }^{10}$ Thin-film transistors made of amorphous oxide semiconductors exhibit a variety of metastable changes in their transistor characteristics through carrier doping and optical ${ }^{11-13}$ or electrical $^{14-21}$ (or both ${ }^{21-28}$ ) excitation of carriers. Indium (In)-based amorphous oxide semiconductors are considered as a promising material for next-generation thin-film electronics and optoelectronics because they have high electron mobility, transparency, flexibility and uniformity. ${ }^{29-33}$ However, the success of these applications has been limited by the lack of stability in their electrical properties owing to charge trapping.

Investigation of the charge-trapping defects on the atomic scale is an essential prerequisite to overcome the instability issue of the indiumbased amorphous oxide semiconductors. An oxygen-vacancy $\left(\mathrm{V}_{\mathrm{O}}\right)$ defect has been suggested as a metastable hole-trap center. ${ }^{34,35}$ Unlike in crystalline oxides, $\mathrm{V}_{\mathrm{O}}$ and $\mathrm{M}$-interstitial $\left(\mathrm{M}_{\mathrm{i}}\right)(\mathrm{M}=\mathrm{In}, \mathrm{Ga}$, or $\mathrm{Zn})$ are essentially indistinguishable in amorphous oxides. An $\mathrm{M}-\mathrm{M}$ bond configuration can be understood as a $\mathrm{V}_{\mathrm{O}}$ and as an $\mathrm{M}_{\mathrm{i}}$ : $\mathrm{O}-(\mathrm{M}-\mathrm{M})$ $\mathrm{O}=\mathrm{O}-\left(\mathrm{M}-\mathrm{V}_{\mathrm{O}}-\mathrm{M}\right)-\mathrm{O}=\mathrm{O}-\left(\mathrm{M}-\mathrm{M}_{\mathrm{i}}\right)-\mathrm{O}$. Similarly, an $\mathrm{O}-\mathrm{O}$ bond configuration can be interpreted as an M-vacancy $\left(\mathrm{V}_{\mathrm{M}}\right)$ and as an
O-interstitial $\left(\mathrm{O}_{\mathrm{i}}\right): \mathrm{M}-(\mathrm{O}-\mathrm{O})-\mathrm{M}=\mathrm{M}-\left(\mathrm{O}-\mathrm{V}_{\mathrm{M}}-\mathrm{O}\right)-\mathrm{M}=\mathrm{M}-\left(\mathrm{O}-\mathrm{O}_{\mathrm{i}}\right)-$ M. Although $\left[\mathrm{O}-\left(\mathrm{M}-\mathrm{V}_{\mathrm{O}}-\mathrm{M}\right)-\mathrm{O}\right]$ and $\left[\mathrm{O}-\left(\mathrm{M}-\mathrm{M}_{\mathrm{i}}\right)-\mathrm{O}\right]$ are the same, the defect properties appear to be different, depending on which term $\left(\mathrm{V}_{\mathrm{O}}\right.$ or $\left.\mathrm{M}_{\mathrm{i}}\right)$ is used because, in crystalline oxides, $\mathrm{V}_{\mathrm{O}}$ and $\mathrm{M}_{\mathrm{i}}$ have quite different properties. Thus, the terminology used for defects in crystalline solids may not be appropriate for use in amorphous solids, leaving the true nature of defects in amorphous solids unclear. ${ }^{36}$ This argument is independent of the charge state of the defects. For $[\mathrm{O}-(\mathrm{M}-\mathrm{M})-\mathrm{O}]$, when one of the M's is divalent $\left(\mathrm{M}_{\mathrm{II}}\right)$, such as $\mathrm{Zn}$, the equivalence is still valid for the (2+) charge state: $\left[\mathrm{O}-\left(\mathrm{M}_{\mathrm{X}}-\mathrm{M}_{\mathrm{II}}\right)-\mathrm{O}\right]^{2+}=\left[\mathrm{O}-\left(\mathrm{M}_{\mathrm{X}}-\mathrm{V}_{\mathrm{O}}{ }^{2+}-\mathrm{M}_{\mathrm{II}}\right)-\mathrm{O}\right]=\left[\mathrm{O}-\left(\mathrm{M}_{\mathrm{X}}-\mathrm{M}_{\mathrm{III}}{ }^{2+}\right)-\mathrm{O}\right]$ ( $\mathrm{X}$ is whatever the valence is). When both $\mathrm{Ms}$ are not divalent, such as trivalent In and $\mathrm{Ga}\left(\mathrm{M}_{\mathrm{III}}\right)$, it is tempting to describe [O- $\left(\mathrm{M}_{\mathrm{III}}-\mathrm{M}_{\mathrm{III}}\right)$ $\mathrm{O}]^{2+}$ as $\left[\mathrm{O}-\left(\mathrm{M}_{\mathrm{III}}-\mathrm{V}_{\mathrm{O}}^{2+}-\mathrm{M}_{\mathrm{III}}\right)-\mathrm{O}\right]$, and $\left[\mathrm{O}-\left(\mathrm{M}_{\mathrm{III}}-\mathrm{M}_{\mathrm{III}}\right)-\mathrm{O}\right]^{3+}$ as $\left[\mathrm{O}-\left(\mathrm{M}_{\mathrm{III}}-\mathrm{M}_{\mathrm{IIIi}}{ }^{3+}\right)-\mathrm{O}\right]$. However, when both the $\mathrm{V}_{\mathrm{O}}{ }^{2+}$ and $\mathrm{M}_{\mathrm{IIIi}}{ }^{3+}$ are shallow donors, where the conduction electrons come from is not clearly identified, and $\left[\mathrm{O}-\left(\mathrm{M}_{\mathrm{III}}-\mathrm{M}_{\mathrm{III}}\right)-\mathrm{O}\right]^{2+}$ and $\left[\mathrm{O}-\left(\mathrm{M}_{\mathrm{III}}-\mathrm{M}_{\mathrm{III}}\right)-\right.$ $\mathrm{O}^{3+}$ are essentially indistinguishable: $3\left[\mathrm{O}-\left(\mathrm{M}_{\mathrm{III}}-\mathrm{M}_{\mathrm{III}}\right)-\mathrm{O}\right]^{2+}=2[\mathrm{O}-$ $\left.\left(\mathrm{M}_{\mathrm{III}}-\mathrm{M}_{\mathrm{III}}\right)-\mathrm{O}\right]^{3+}+\left[\mathrm{O}-\left(\mathrm{M}_{\mathrm{III}}-\mathrm{M}_{\mathrm{III}}\right)-\mathrm{O}\right]^{0}$. Thus, there is still a problem with the definition of vacancy and interstitial defects in amorphous solids, even with considering metal valency. Meta-stable peroxide $\left(\mathrm{O}_{2}{ }^{2-}\right)$ defects that are created by excited holes ${ }^{37}$ and $\left[\mathrm{O}_{\mathrm{i}}{ }^{2-}+2 \mathrm{H}_{\mathrm{i}}^{+}\right]$ defects $^{38}$ have been suggested as hole-trap centers. An excess $\mathrm{O}$ defect model has been previously suggested to describe electron-trap centers based on ozone-treated amorphous $\mathrm{InGaZnO}_{4} \cdot{ }^{39}$ The excess $\mathrm{O}$ is characterized as a weakly binding $\mathrm{O}$ that results in a peak at $\sim 200^{\circ} \mathrm{C}$ in thermal desorption spectroscopy. Thus, the excess $\mathrm{O}$ can be removed using a thermal annealing process. ${ }^{36,39}$ Because electron trapping still occurs in the absence of excess $\mathrm{O}$, there should be another cause of electron trapping.

${ }^{1}$ Center for Correlated Electron Systems, Institute for Basic Science (IBS), Seoul, Korea; ${ }^{2}$ Department of Physics and Astronomy, Seoul National University, Seoul, Korea; ${ }^{3}$ Korea Research Institute of Standards and Science, Daejeon, Korea and ${ }^{4}$ Department of Nano Science, University of Science and Technology, Daejeon, Korea Correspondence: Dr Y-S Kim, Nano characterization center, Korea Research Institute of Standards and Science, 1 Doryong Yuseong, Daejeon 305-340, Korea. E-mail: kimyongsung@gmail.com 
In this paper, we find that undercoordinated indium $\left(\operatorname{In}^{\star}\right)$ acts as an intrinsic electron-trap center in In-based amorphous oxide semiconductors. Conduction electrons are subjected to a strong conductionelectron-ion interaction near the undercoordinated $\mathrm{In}^{\star}$ and trapped there, forming an $\mathrm{In}^{\star}-\mathrm{M}$ bond. The electron-trapped center is stable in the (2-) charge state; thus, we designate it as a negatively double-charged intrinsic $\left(\mathrm{In}^{*}-\mathrm{M}\right)^{2-}$ center in amorphous oxide semiconductors.

\section{MATERIALS AND METHODS}

Amorphous $\mathrm{InGaZnO}_{4}$ is considered as a prototype In-based amorphous oxide semiconductor. For theoretical investigations, the amorphous structures are generated using a melt-and-quench molecular dynamics simulations, ${ }^{37}$ and the structural instability of the conduction electrons and the electronic structures are investigated using density-functional theory calculations. ${ }^{40,41}$ The projectoraugmented wave pseudopotentials $s^{42,43}$ and the plane wave basis set with a kinetic energy cutoff of $400 \mathrm{eV}$ are used. The hybrid functional of HeydScuseria-Ernzerhof with a mixing parameter of 0.25 and a screening parameter of $0.2 \AA^{-1}$ is used for the exchange-correlation energy of the electrons. ${ }^{44,45} \mathrm{~A}$ rhombohedral 112-atom supercell is adopted, and a $2 \times 2 \times 2 k$-point mesh is used for the Brillouin zone summation. The dimer method is used to find the transition state in the structural changes. ${ }^{46}$ In the charged state calculations, for the localized charges, we correct the spurious electrostatic interaction energies between the image charges in supercells using a model charge correction scheme. $^{47-49}$

\section{RESULTS AND DISCUSSION}

The charge density of the lowest conduction band in amorphous InGaZnO${ }_{4}$ is shown in Figure 1a. The conduction electrons are delocalized as expected because, in amorphous $\mathrm{InGaZnO}_{4}$, the lowest conduction band states are mainly characterized by the In-5s-like atomic orbital states, and their effective overlap through the In atomic sites results in a low electron effective mass, which is the reason for the high electron mobility in amorphous $\mathrm{InGaZnO}_{4}$. Interestingly, the $s$-like conduction electrons in amorphous $\mathrm{InGaZnO}_{4}$ are not found to be homogeneous, but they are highly concentrated in the depicted the local atomic structure as shown in Figure 1a.

The place where the conduction electrons are highly concentrated is found to be near the undercoordinated $\mathrm{In}^{*}$ atom. In crystalline Inoxides, such as $\mathrm{In}_{2} \mathrm{O}_{3}$ and crystalline $\mathrm{InGaZnO}_{4}$, the In atoms have sixfold coordination with nearby $\mathrm{O}$ atoms. In amorphous $\mathrm{InGaZnO}_{4}$, the coordination number of some In atoms, such as the In depicted in Figure 1a, is depleted to fivefold coordination, and the mean value of the In coordination number has been measured to be $\sim 5.5$ (see the running coordination numbers and shaded region in Figure 1b). ${ }^{50} \mathrm{In}$ Figure 1c, we plot the integrated charges in the Wigner-Seitz volume around the In atoms with a radius of $1.677 \AA$, as a function of the In coordination number. The In coordination number is determined by counting the number of $\mathrm{O}$ atoms that have a valence charge density minimum along the In-O lines higher than $0.2 \mathrm{ea} / \AA^{3}$. This criterion approximately corresponds with the number of $\mathrm{O}$ atoms within $2.6 \AA$ of the central In atom. There is a tendency that the integrated charge increases as the In coordination number decreases. The In $^{\star}$ atom indicated by the red circle in Figure 1c is fivefold coordinated and has the highest local-integrated charge among the In atoms in the system, indicating structural instability, which will be discussed below. The local deficiency of $\mathrm{O}$ atoms around the In atom can accommodate the conduction electrons most likely via electrostatic attraction, which is important in ionically bonded materials. The variation in the integrated charges with the same In coordination number observed in Figure 1c can be attributed to strained In-O bonds and a variety of local-field effects in the amorphous structure. Conduction electron crowding can occur near an In atom in amorphous $\mathrm{InGaZnO}_{4}$, and the undercoordinated In atoms are more likely to be the $\operatorname{In}^{*}$ atoms, which can accommodate more conduction electrons. Conduction electron crowding does not occur at all of the undercoordinated In a

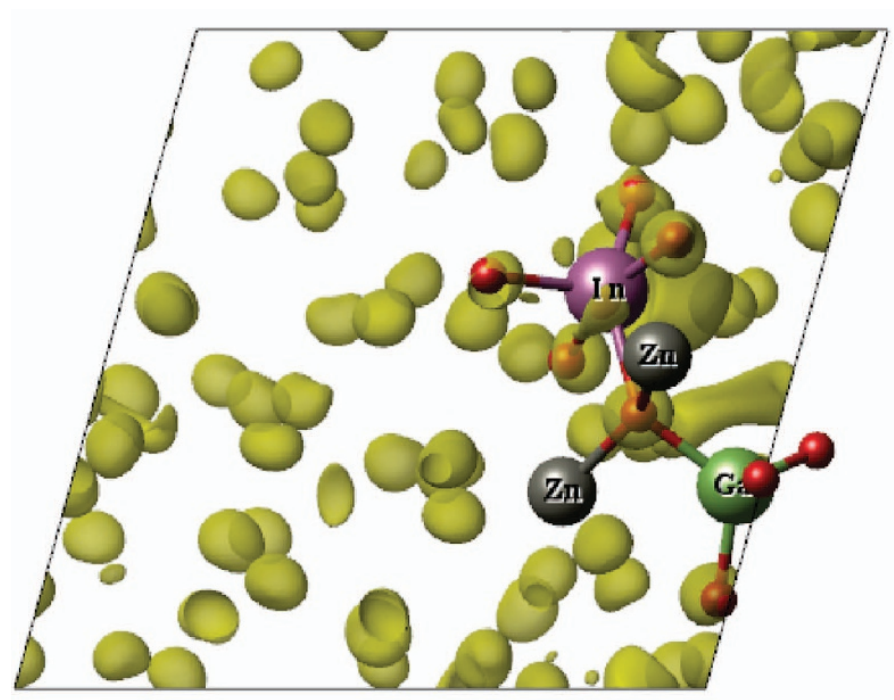

b
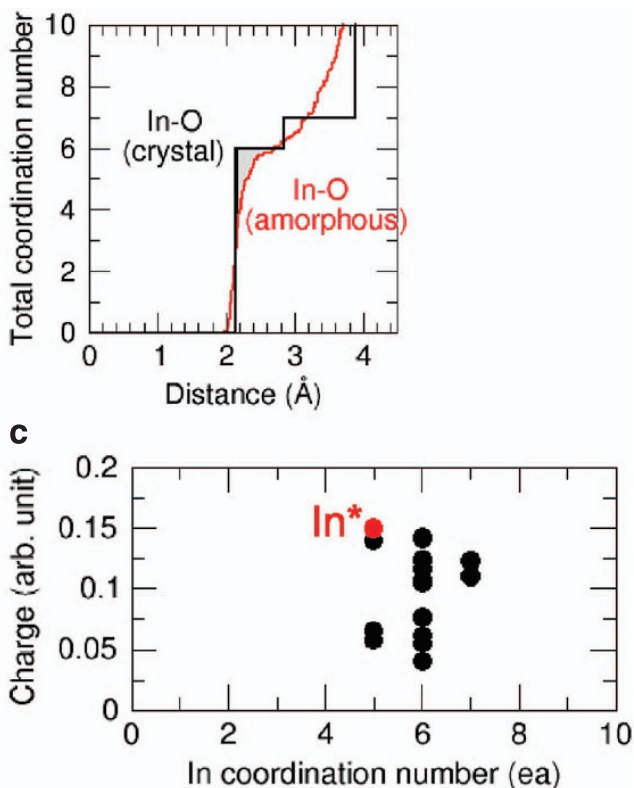

Figure 1 (a) Charge density of the lowest conduction band in amorphous InGaZnO $\mathrm{n}_{4}$. The local atomic structure is shown where the conduction electrons are crowded. The In, Ga and $\mathrm{Zn}$ atoms are as indicated in the figure, and the $\mathrm{O}$ atoms are indicated by the small (red) atoms. The charge density isosurface is 0.001 e per supercell. (b) Running coordination numbers of In with $\mathrm{O}$ in crystalline (black) and amorphous (red) InGaZnO ${ }_{4}$. (c) Integrated conduction electron charge inside the Wigner-Seitz volume around the In atoms in the supercell as a function of the In coordination number. The red dot (In*) is for the In atom shown in (a). 
atoms, but at least one $\left(\operatorname{In}^{*}\right)$ of the undercoordinated In atoms in the system experiences electron crowding.

The conduction electron crowding near the undercoordinated $\operatorname{In}^{*}$ implies strong conduction-electron-ion interaction. We placed two electrons $\left(2 \mathrm{e}^{-}\right)$in a 112-atom supercell $\left(1.553 \times 10^{21} \mathrm{~cm}^{-3}\right)$ and investigated the changes in the atomic structure. The charge neutrality is satisfied by assuming a uniform background $(2+)$ charge. In the presence of conduction electrons, the original $\mathrm{In}^{*}$ configuration (Figure 2a) is no longer stable, but a new $\operatorname{In}^{\star}-\mathrm{M}$ bond (in this case, an In $^{\star}-\mathrm{Ga}$ bond) configuration (Figure $2 \mathrm{c}$ ) is generated. Because the conduction electrons are more concentrated near the undercoordinated $\mathrm{In}^{\star}$, the atomic structure near the $\mathrm{In}^{\star}$ atom is affected by them. We denote the original atomic configuration as the normal state (NS) and the $\mathrm{In}^{*}-\mathrm{M}$ bond configuration as the electron-trapped state $\left(\mathrm{In}^{*}\right.$ $\mathrm{M})$. The transition state (TS) between them is shown in Figure $2 \mathrm{~b}$.

We would like to describe the changes in the atomic structure between NS and $\mathrm{In}^{*}-\mathrm{M}$. An $\mathrm{O}$ atom that has a tetrahedral bonding configuration with one $\mathrm{In}^{*}$, one $\mathrm{Ga}$ and two $\mathrm{Zn}$ (see Figure 2a) is significantly displaced toward the midpoint between the two $\mathrm{Zn}$, far away from the $\operatorname{In}^{*}$ and $\mathrm{Ga}$ atoms (by $1.448 \AA$ at the $\mathrm{In}^{*}-\mathrm{M}$ ), which results in (i) breaking two $\mathrm{M}-\mathrm{O}\left(\mathrm{In}^{*}-\mathrm{O}\right.$ and $\left.\mathrm{Ga}-\mathrm{O}\right)$ bonds and (ii) formation of one new $\mathrm{In}^{*}-\mathrm{M}\left(\mathrm{In}^{*}-\mathrm{Ga}\right)$ bond, as shown in Figure $2 \mathrm{c}$. The coordination numbers of $\mathrm{Zn}$ and $\mathrm{In}$ in the bottom left of Figure $2 \mathrm{c}$ are increased by 1 (from 4 to 5 for $\mathrm{Zn}$ and from 5 to 6 for In bonding with $\mathrm{O}$ ) due to the structural change. This structural change reminds us of the well-known double-broken-bond DX state in crystalline semiconductors, ${ }^{2,5-7}$ which is formed when a donor impurity traps electrons. The $\mathrm{In}^{\star}-\mathrm{M}$ (Figure $2 \mathrm{c}$ ) is an electron trap as well, but it is intrinsic in amorphous $\mathrm{InGaZnO}_{4}$. It can be interpreted as a small polaron that is more strongly localized after forming the $\mathrm{In}^{\star}-\mathrm{M}$ bond.

Figure 3 shows the calculated local electronic density-of-states near the $\mathrm{In}^{*}$ and $\mathrm{Ga}$ atoms, as the NS is transformed into the $\mathrm{In}^{*}-\mathrm{M}$ structure in the (2-) charge state. In the NS+2 $e^{-}$, there is a defect state inside the conduction band (indicated by $\operatorname{In}^{\star}$ at the top of Figure 3 ) that originates from the undercoordinated $\mathrm{In}^{\star}$ atom. The charge density shown in Figure 1a includes this defect state. As the NS+2 $e^{-}$is transformed into $\left(\mathrm{In}^{*}-\mathrm{M}\right)^{2-}$, the defect level decreases; at $\mathrm{TS}^{2-}$, the defect level crosses the Fermi level near the conduction band minimum, and then, the defect state emerges inside the band gap, which is occupied by two electrons. In $\left(\operatorname{In}^{*}-\mathrm{M}\right)^{2-}$, we find a well-isolated state inside the band gap. The charge density of the $\left(\mathrm{In}^{*}-\mathrm{M}\right)^{2-}$ deep state is shown in the inset of Figure 3 and characterized by the $\mathrm{In}^{*}-\mathrm{Ga} s s \sigma$ bonding and $\left(\mathrm{In}^{\star} / \mathrm{Ga}\right)-\mathrm{O} s p \sigma^{*}$ antibonding molecular orbitals. The deep gap state basically originates
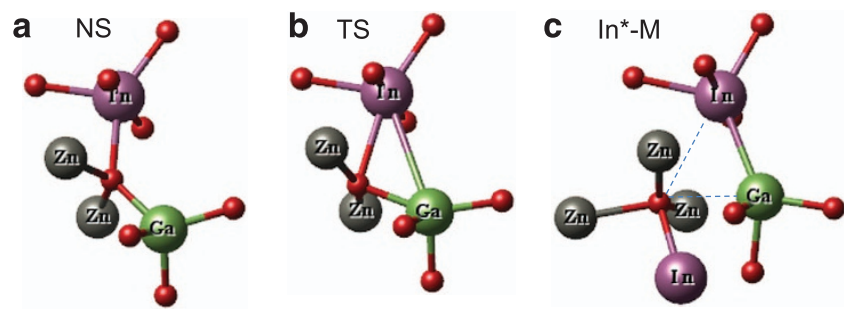

Figure 2 (a) Local atomic structure in amorphous InGaZnO ${ }_{4}$ in which the In atom is fivefold coordinated. (b) The transition state (TS) in the structural transition between the NS and $I n *-M$ state in the $(2-)$ charge state. (c) Atomic structure of the $I n *-M$ state. The $I n, G a$ and $\mathrm{Zn}$ atoms are as indicated in the figures, and the $\mathrm{O}$ atoms are indicated by the small (red) atoms. from the large double-broken-bond distortion from the conduction electrons via the strong conduction-electron-ion interaction near the undercoordinated $\mathrm{In}^{*}$.

The $\mathrm{In}^{\star}-\mathrm{Ga} s s \sigma$ bonding and $\left(\mathrm{In}^{\star} / \mathrm{Ga}\right)-\mathrm{O} s p \sigma^{\star}$ antibonding nature of the $\left(\operatorname{In}^{*}-\mathrm{M}\right)^{2-}$ defect state governs the structural feature of the transition between the NS+2 $\mathrm{e}^{-}$and $\left(\mathrm{In}^{\star}-\mathrm{M}\right)^{2-}$. When the Fermi level is near the conduction band minimum in the NS configuration, the $2 \mathrm{e}^{-}$conduction electrons partially occupy the $\operatorname{In}^{\star}$ states, which are the crowded electrons near the undercoordinated $\operatorname{In}^{\star}$ as shown in Figure 1. If the $\left(\mathrm{In}^{\star} / \mathrm{Ga}\right)-\mathrm{O} s p \sigma^{*}$ antibonding and $\mathrm{In}^{*}-\mathrm{Ga} s s \sigma$ bonding levels are partially occupied (from $\mathrm{NS}+2 \mathrm{e}^{-}$to $\mathrm{TS}^{2-}$ ), the $\left(\mathrm{In}^{\star} / \mathrm{Ga}\right)-\mathrm{O}$ bond lengths tend to increase, and the $\operatorname{In}^{*}-\mathrm{Ga}$ bond length decreases. When it is fully occupied (from $\mathrm{TS}^{2-}$ to $\left(\mathrm{In}^{\star}-\mathrm{M}\right)^{2-}$ ), the $\left(\mathrm{In}^{\star} / \mathrm{Ga}\right)-\mathrm{O}$ bonds are broken, with the distances between the $\left(\mathrm{In}^{\star} / \mathrm{Ga}\right)$ and $\mathrm{O}$ further increased via the formation of the $\operatorname{In}^{\star}-\mathrm{Ga}$ bond, and the structure is spontaneously transformed into the stable $\left(\operatorname{In}^{*}-\mathrm{M}\right)^{2-}$ state. That is, the conduction electrons contribute to the formation of the $\left(\operatorname{In}^{*}-\mathrm{M}\right)^{2-}$ state through traps near the undercoordinated $\operatorname{In}^{\star}$ atom that shares $\operatorname{In}^{\star}-$ Ga $s s \sigma$ bonding and $\left(\mathrm{In}^{\star} / \mathrm{Ga}\right)-\mathrm{O} s p \sigma^{\star}$ antibonding orbitals with nearby atoms.

The electron trap and detrap mechanisms in amorphous oxide semiconductors can, therefore, be expressed by the reaction

$$
\mathrm{NS}+2 \mathrm{e}^{-} \leftrightarrow\left(\mathrm{In}^{*}-\mathrm{M}\right)^{2-} .
$$

The calculated potential energy surfaces in the structural transition between the NS and $\mathrm{In}^{*}-\mathrm{M}$ configurations are shown in Figure $4 \mathrm{a}$ in the neutral and $(2-)$ charged states. In the neutral state, only the NS is stable, whereas the $\left(\mathrm{In}^{*}-\mathrm{M}\right)^{0}$ is naturally unstable. In the $(2-)$ charge state, $\left(\operatorname{In}^{\star}-\mathrm{M}\right)^{2-}$ is found to be more stable by $0.25 \mathrm{eV}$ than NS $+2 \mathrm{e}^{-}$. The energy barrier in the structural transition from NS+2 $\mathrm{e}^{-}$to $\left(\mathrm{In}^{\star}-\mathrm{M}\right)^{2-}($ denoted as $\alpha)$ is $0.49 \mathrm{eV}$. The large $\alpha$ barrier represents the energy required to fully occupy the $\operatorname{In}^{*}-\mathrm{Ga} s s \sigma$ bonding and $\left(\operatorname{In}^{\star} /\right.$ $\mathrm{Ga}$ )-O $s p \sigma^{*}$ antibonding states in the NS configuration (as shown in Figure 3), and thus, the $\alpha$ barrier depends on the electron carrier concentration $(n)$. We calculate the $\alpha$ barriers with excess electrons, that is, $(3-),(4-),(5-),(6-)$ and $(8-)$, in the supercell with the

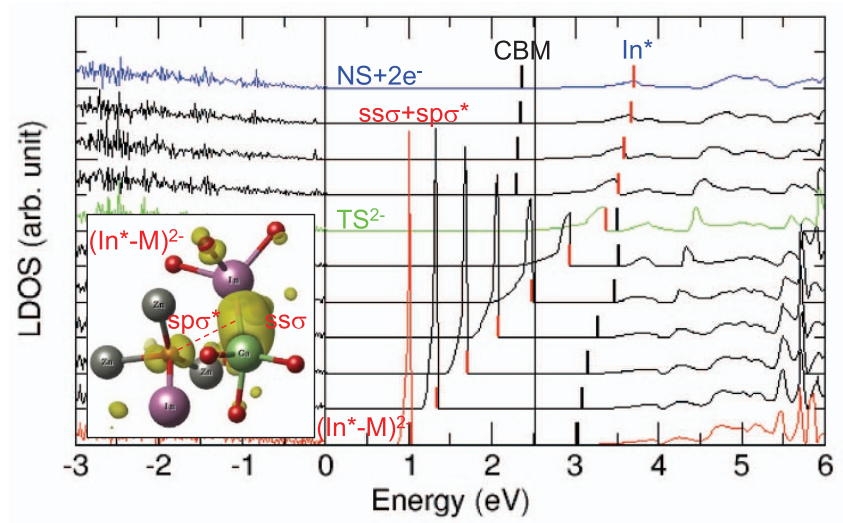

Figure 3 Local electronic density-of-states (LDOS) around the Ga and In atoms (see the text) for the $N S+2 e^{-}$(blue) and $\left(\mathrm{In}^{*}-\mathrm{M}\right)^{2-}$ (red) configurations. The LDOS evolution between the NS+2 $\mathrm{e}^{-}$and $\left(\mathrm{In}^{*}-\mathrm{M}\right)^{2-}$ is also shown with the LDOS for the transition state $\left(\mathrm{TS}^{2-}{ }^{-}\right.$) (green). The valence band maximum is at the zero energy, the highest occupied levels are indicated by the (red) short lines, and the CBMs are indicated by the (black) short lines. The CBM of neutral NS is indicated by the vertical line at $2.5 \mathrm{eV}$. The charge density of the $\left(\mathrm{In}^{*}-\mathrm{M}\right)^{2-}$ defect state inside the band gap is shown in the inset. The charge density isosurface is $0.008 e$ per supercell. 
a

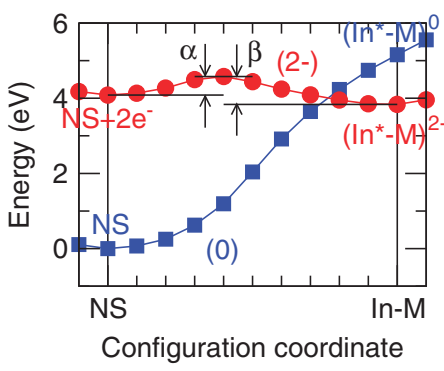

b

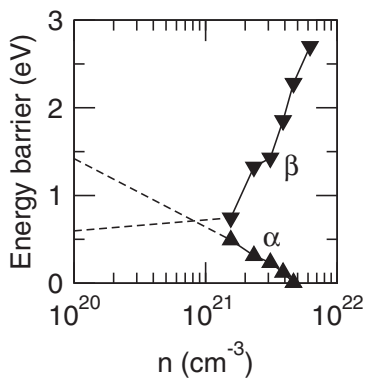

Figure 4 (a) Energy surfaces in the structural transition between the NS and $\left(I n^{*}-\mathrm{M}\right)$ configuration in the neutral (blue squares) and $(2-)$ (red circles) charge state. The NS energy is set to zero, and the electronic chemical potential is supposed to be at the Fermi level of the neutral NS $(1.3 \mathrm{eV}$ above the valence band maximum). (b) Calculated $\alpha(\boldsymbol{\Lambda})$ and $\beta(\boldsymbol{\nabla})$ energy barriers are plotted with respect to the electron carrier concentration ( $n$ ). The dashed lines are extrapolations to $n=0$.

same number of positive uniform background charges. They correspond to $1.553,2.330,3.106,3.883,4.659$ and $6.212 \times 10^{21} \mathrm{~cm}^{-3}$, respectively. The calculated $\alpha$ energy barrier as a function of $n$ is shown in Figure $4 \mathrm{~b}$, which is reduced with increasing $n$. When the carrier density is $4.7 \times 10^{21} \mathrm{~cm}^{-3}$, the $\alpha$ barrier is found to be zero.

The structural recovery from $\left(\mathrm{In}^{*}-\mathrm{M}\right)^{2-}$ to the NS+2 $\mathrm{e}^{-}$state can take place when the deep $\left(\mathrm{In}^{*}-\mathrm{M}\right)^{2-}$ electronic state inside the band gap releases the two electrons. The $\left(\mathrm{In}^{\star}-\mathrm{M}\right)^{2-}$ level can be increased from $\left(\mathrm{In}^{\star}-\mathrm{M}\right)^{2-}$ to $\mathrm{TS}^{2-}$ in Figure 3 by thermal excitation, and when it crosses the Fermi level, the two trapped electrons are released. The recovery energy barrier $(\beta)$ through the thermal process is calculated to be $0.74 \mathrm{eV}$, as shown in Figure $4 \mathrm{a}$, which increases as the conduction electron density increases (the level of the Fermi sea is higher). The structural recovery can also occur via optical or electrical excitation of the $\left(\mathrm{In}^{*}-\mathrm{M}\right)^{2-}$ electrons into the empty conduction bands. For the $\left(\mathrm{In}^{\star}-\mathrm{M}\right)^{2-} \rightarrow \mathrm{NS}+2 \mathrm{e}-$ detrapping process, the required photon energy depends on the Fermi level, and when it is at the conduction band minimum, the minimum required photon energy is estimated to be $2.1 \mathrm{eV}$.

The electron-trapping $\left(\mathrm{In}^{*}-\mathrm{M}\right)^{2-}$ centers are likely to form in heavily $n$-doped amorphous $\mathrm{InGaZnO}_{4}$. $\left(\mathrm{In}^{*}-\mathrm{M}\right)^{2-}$ acts as a donorcompensating center that reduces the electron carrier concentration. Experimentally, the carrier concentration in $n$-type amorphous $\mathrm{InGaZnO}_{4}$ has not surpassed $10^{20} \mathrm{~cm}^{-3}$ (the doping limit) by controlling oxygen partial pressure or hydrogen incorporation. ${ }^{51}$ The doping limit has been measured to be much lower than the dopant concentration, ${ }^{51}$ implying the presence of deep electrontrapping centers in amorphous $\mathrm{InGaZnO}_{4} \cdot{ }^{32,52}$

The formation of $\left(\mathrm{In}^{*}-\mathrm{M}\right)^{2-}$ can also occur by optical or electrical excitation of electrons as the $n$-type doping in amorphous $\mathrm{InGaZnO}_{4}$. Electrical stress, positive gate bias stress (PBS) or current stress (CS), in which the (n-type) thin-film transistors are turned on, can be applied, and the threshold voltage has been known to be positively shifted owing to its metastability. PBS and CS generate a high concentration of carrier electrons in the amorphous $\mathrm{InGaZnO}_{4}$ channel, and via the forward reaction in Equation (1), electron trapping $\left(\operatorname{In}^{*}-\mathrm{M}\right)^{2-}$ centers can be formed. A negatively charged deep level has been hypothesized to be created in experiments, accompanied by a positive shift of the threshold voltage. ${ }^{20}$

The experimentally measured thermal activation energy for electron trapping $\left(\mathrm{E}_{\mathrm{a} \text {,trap }}\right)$ is in the range of $0.22-0.95 \mathrm{eV}^{15-19,22}$ under PBS and

$0.08-0.14 \mathrm{eV}^{20}$ under CS. The $\alpha$ energy barrier in the $\left(\mathrm{In}^{*}-\mathrm{M}\right)^{2-}$ formation corresponds to these values, which vary depending on the carrier concentration (Figure 4b). For $n<10^{21} \mathrm{~cm}^{-3}$, a larger supercell is needed, which is not currently accessible, but it can be extrapolated to the $n=0$ limit $(\alpha=5.2 \mathrm{eV}$ and $\beta=0 \mathrm{eV}$ in the neutral state as shown in Figure 4a). In the range of $n>10^{20} \mathrm{~cm}^{-3}$, which is typical under PBS and CS conditions, the estimated $\alpha$ energy barriers are 0.0 $1.4 \mathrm{eV}$ in good agreement with the experiments $(0.08-0.95 \mathrm{eV}) .{ }^{15-20,22}$ The thermal activation energy for electron detrapping $\left(\mathrm{E}_{\mathrm{a}}\right.$, detrap) (after stopping the PBS or CS) has also been measured. This value can be interpreted as the $\beta$ energy barrier in the $\left(\mathrm{In}^{*}-\mathrm{M}\right)^{2-} \rightarrow \mathrm{NS}+2 \mathrm{e}^{-}$ transition. Without external stresses, the carrier density is typically $n<10^{20} \mathrm{~cm}^{-3}$ (below the doping limit) in the presence of both normal shallow donors and electron-trapping $\left(\mathrm{In}^{*}-\mathrm{M}\right)^{2-}$ centers, and the estimated $\beta$ energy barriers are $0.0-0.7 \mathrm{eV}$ in the $n$ range. The measured values are $\mathrm{E}_{\mathrm{a} \text {,detrap }}=0.23$ and $0.97 \mathrm{eV}^{22,19}$

The issue that a uniform background charge with PAW formalism gives rise to an additional total energy term has been recently addressed. ${ }^{53}$ This term is not included in this study, and the energies obtained are only qualitative at best. For the $(2-)$ charge state, the error is typically $<0.2 \mathrm{eV}$ according to reference ${ }^{53}$, which is smaller than the energy differences obtained in this study. Therefore, we do not need to make any qualitative changes to our conclusions. The $\alpha$ and $\beta$ barrier estimations shown in Figure $4 \mathrm{~b}$ could be quantitatively affected by the additional total energy term, but their trends would be unaffected.

\section{CONCLUSIONS}

In conclusion, an intrinsic electron-trapping center in amorphous InGaZnO ${ }_{4}$ is identified. The conduction electrons are attracted to undercoordinated $\mathrm{In}^{\star}$ and subjected to a strong electron-ion interaction. The driving force to form $\mathrm{In}^{\star}-\mathrm{M}$ bonds is induced by trapped electrons. The negatively double-charged (electron-trapped) intrinsic $\left(\mathrm{In}^{*}-\mathrm{M}\right)^{2-}$ centers in amorphous $\mathrm{InGaZnO}_{4}$ have an important role in pinning the Fermi level in heavily $n$-doped samples, and metastable positive-shifts of the threshold voltage in thin-film transistors under PBS or CS, which generate excited electrons. To suppress the PBS and CS instabilities and enhance the $n$-doping limit, a reduction in the number of undercoordinated $\mathrm{In}^{*}$ in amorphous $\mathrm{InGaZnO}_{4}$ is essential.

\section{CONFLICT OF INTEREST}

The authors declare no conflict of interest.

\section{ACKNOWLEDGEMENTS}

YSK acknowledges support from the Nano R\&D Program through the National Research Foundation (NRF) of Korea (NRF-2009-0082489), and HHN acknowledges support from the Institute for Basic Science (IBS) in Korea. Author contributions: HHN provided the main idea and performed the calculations. YSK wrote the manuscript, performed some calculations for confirmation and made the interpretations.

1 Chadi, D. J. \& Chang, K. J. Theory of the atomic and electronic structure of DX Ccenters in GaAs and $\mathrm{Al}_{x} \mathrm{Ga}_{1-\mathrm{x}}$ As Alloys. Phys. Rev. Lett. 61, 873 (1988).

2 Park, C. H. \& Chadi, D. J. Orthorhombic symmetry DX centers in S-doped GaSb, GaAs, and $\mathrm{Al}_{x} \mathrm{Ga}_{1-x}$ As. Phys. Rev. B 54, 14246 (1996).

3 Zhang, S. B., Wei, S.-H. \& Zunger, A. Microscopic origin of the phenomenological equilibrium "Doping Limit Rule" in n-Type III-V semiconductors. Phys. Rev. Lett. 84 1232 (2000).

4 Lany, S. \& Zunger, A. Intrinsic DX centers in ternary chalcopyrite semiconductors. Phys Rev. Lett. 100, 016401 (2008). 
5 Park, C. H. \& Chadi, D. J. Stability of deep donor and acceptor centers in GaN, AIN, and BN. Phys. Rev. B 55, 12995 (1997).

6 Park, C. H. \& Chadi, D. J. Bulk lattice instability in II-VI semiconductors and its effect on impurity compensation. Phys. Rev. Lett. 75, 1134 (1995).

7 Park, C. H., Zhang, S. B. \& Wei, S.-H. Origin of p-type doping difficulty in ZnO: the impurity perspective. Phys. Rev. B 66, 073202 (2002).

8 Takechi, K., Nakata, M., Eguchi, T., Yamaguchi, H. \& Kaneko, S. Comparison of ultraviolet photo-field effects between hydrogenated amorphous silicon and amorphous InGaZnO4 thin-film transistors. Jpn J. Appl. Phys. 48, 010203 (2009).

9 Wegener, H. A. R., Lincoln, A. J., Pao, H. C., O'Connell, M. R., Oleksiak, R. E. \& Lawrence, H. The variable threshold transistor, a new electrically-alterable, nondestructive read-only storage device. IEDM Tech. Digest 13, 70 (1967).

10 Lee, D. H., Kawamura, K., Nomura, K., Kamiya, T. \& Hosono, H. Large photoresponse in amorphous In-Ga- $\mathrm{Zn}-\mathrm{O}$ and origin of reversible and slow decay. Electrochem. SolidState Lett 13, H324 (2010).

11 Barquinha, P., Pimentel, A., Marques, A., Pereira, L., Martins, R. \& Fortunato, E. Effect of UV and visible light radiation on the electrical performances of transparent TFTs based on amorphous indium zinc oxide. J. Non-Cryst. Solids 352, 1756 (2006).

12 Görrn, P., Lehnhardt, M., Riedl, T. \& Kowalsky, W. Effect of UV and visible light radiation on the electrical performances of transparent TFTs based on amorphous indium zinc oxide. Appl. Phys. Lett. 91, 193504 (2007)

13 Gosain, D. P. \& Tanaka, T. Instability of amorphous indium gallium zinc oxide thin film transistors under light illumination. Jpn. J. Appl. Phys. 48, 03B018 (2009).

14 Görrn, P., Hölzer, H., Kowalsky, W., Wang, J., Weimann, T., Hinze, P. \& Kipp, S. Stability of transparent zinc tin oxide transistors under bias stress. Appl. Phys. Lett. 90, 063502 (2007)

15 Suresh, A. \& Muth, J. F. Bias stress stability of indium gallium zinc oxide channel based transparent thin film transistors. Appl. Phys. Lett. 92, 033502 (2008).

16 Lee, J. M., Cho, I. T., Lee, J. H. \& Kwon, H. I. Bias-stress-induced stretchedexponential time dependence of threshold voltage shift in InGaZnO thin film transistors. Appl. Phys. Lett. 93, 093504 (2008).

17 Lopes, M. E., Gomes, H. L., Medeiros, M. C. R., Barquinha, P., Pereira, L., Fortunato, E., Martins, R. \& Ferreira, I. Gate-bias stress in amorphous oxide semiconductors thin-film transistors. Appl. Phys. Lett. 95, 063502 (2009).

18 Fung, T. C., Abe, K., Kumomi, H. \& Kanicki, J. Electrical instability of RF sputter amorphous In-Ga-Zn-O thin-film transistors. J. Disp. Technol. 5, 452 (2009).

19 Chowdhury, M. D. H., Migliorato, P. \& Jang, J. Time-temperature dependence of positive gate bias stress and recovery in amorphous indium-gallium-zinc-oxide thin-filmtransistors. Appl. Phys. Lett. 98, 153511 (2011).

20 Nomura, K., Kamiya, T., Hirano, M. \& Hosono, H. Origins of threshold voltage shifts in room-temperature deposited and annealed a-In-Ga-Zn-O thin-film transistors. Appl. Phys. Lett. 95, 013502 (2009).

21 Nomura, K., Kamiya, T. \& Hosono, H. Highly stable amorphous In-Ga-Zn-O thin-film transistors produced by eliminating deep subgap defects. Appl. Phys. Lett. 99, 053505 (2011)

22 Chen, T. C., Chang, T. C., Tsai, C. T., Hsieh, T. Y., Chen, S. C., Lin, C. S., Hung, M. C., Tu, C. H., Chang, J. J. \& Chen, P. L. Behaviors of InGaZnO thin film transistor under illuminated positive gate-bias stress. Appl. Phys. Lett. 97, 112104 (2010)

23 Oh, H., Yoon, S.-M., Ryu, M. K., Hwang, C.-S., Yang, S. \& Park, S.-H. K. Photonaccelerated negative bias instability involving subgap states creation in amorphous InGa-Zn-0 thin film transistor. Appl. Phys. Lett 97, 183502 (2010).

24 Chowdhury, M. D. H., Migliorato, P. \& Jang, J. Light induced instabilities in amorphous indium-gallium-zinc-oxide thin-film transistors. Appl. Phys. Lett. 97, 173506 (2010).

$25 \mathrm{Ji}$, K. H. Kim, J.-I., Jung, H. Y., Park, S. Y., Choi, R., Mo, Y. G. \& Jeong, J. K. Comprehensive studies of the degradation mechanism in amorphous InGaZnO transistors by the negative bias illumination stress. Microelectron. Eng. 88, 1412 (2011).

26 Oh, H. Yoon, S.-M., Ryu, M. K., Hwang, C.-S., Yang, S. \& Park, S.-H. K. Transition of dominant instability mechanism depending on negative gate bias under illumination in amorphous In-Ga-Zn-O thin film transistor. Appl. Phys. Lett. 98, 033504 (2011).

27 Chen, W.-T., Hsueh, H.-W., Zan, H.-W. \& Tsai, C.-C. Light-enhanced bias stress effect on amorphous In-Ga-Zn-O thin-film transistor with lights of varying colors. Electrochem. Solid St. 14, H297 (2011).

28 Kim, J. H., Kim, U. K., Chung, Y. J. \& Hwang, C. S. Correlation of the change in transfer characteristics with the interfacial trap densities of amorphous In-Ga-Zn-0 thin film transistors under light illumination. Appl. Phys. Lett. 98, 232102 (2011).

29 Nomura, K., Ohta, H., Takagi, A., Kamiya, T., Hirano, M. \& Hosono, H. Roomtemperature fabrication of transparent flexible thin-film transistors using amorphous oxide semiconductors. Nature 432, 488 (2004).

30 Kamiya, T., Nomura, K. \& Hosono, H. Origins of high mobility and low operation voltage of amorphous oxide TFTs: electronic structure, electron transport, defects and doping. J. Disp. Technol. 5, 273 (2009).

31 Kamiya, T., Nomura, K. \& Hosono, H. Present status of amorphous In-Ga-Zn-0 thinfilm transistors. Sci. Technol. Adv. Mater. 11, 044305 (2010).
32 Fortunato, E., Barquinha, P. \& Martins, R. Oxide Semiconductor thin-film transistors: a review of recent advances. Adv. Mater. 24, 2945 (2012).

33 Siah, S. C., Lee, S. W. Lee, Y. S., Heo, J. Shibata, T., Segre, C. U, Gordon, R. G. \& Buonassisi, T. X-ray absorption spectroscopy elucidates the impact of structural disorder on electron mobility in amorphous zinc-tin-oxide thin films. Appl. Phys. Lett. 104, 242113 (2014)

34 Ryu, B., Noh, H.-K., Choi, E.-A. \& Chang, K. J. O-vacancy as the origin of negative bias illumination stress instability in amorphous $\mathrm{In}-\mathrm{Ga}-\mathrm{Zn}-\mathrm{O}$ thin film transistors. Appl. Phys. Lett. 97, 022108 (2010).

35 Noh, H.-K., Chang, K. J., Ryu, B. \& Lee, W.-J. Electronic structure of oxygen-vacancy defects in amorphous In-Ga-Zn-O semiconductors. Phys. Rev. B 84, 115205 (2011).

36 Sallis, S., Butler, K. T., Quackenbush, N. F., Williams, D. S., Junda, M., Fischer, D. A., Woicik, J. C., Podraza, N. J., White, B. E. Jr., Walsh, A. \& Piper, L. F. J. Origin of deep subgap states in amorphous indium gallium zinc oxide: chemically disordered coordination of oxygen. Appl. Phys. Lett. 104, 232108 (2014).

$37 \mathrm{Nahm}, \mathrm{H} .-\mathrm{H} .$, Kim, Y.-S. \& Kim, D. H. Instability of amorphous oxide semiconductors via carrier-mediated structural transition between disorder and peroxide state. Physica. Status Solidi. B 249, 1277 (2012)

38 Robertson, J. \& Guo, Y. Light induced instability mechanism in amorphous InGaZn oxide semiconductors. Appl. Phys. Lett. 104, 162102 (2014).

39 Ide, K., Kikuchi, Y., Nomura, K., Kimura, M., Kamiya, T. \& Hosono, H. Effect of excess oxygen on operation characteristics of amorphous In-Ga-Zn-O thin-film transistors. Appl. Phys. Lett. 99, 093507 (2011).

40 Kresse, G. \& Furthmüller, J. Efficiency of ab-initio total energy calculations for metals and semiconductors using a plane-wave basis set. Comput. Mater. Sci. 6, 15 (1996)

41 Kresse, G. \& Furthmüller, J. Efficient iterative schemes for ab initio total-energy calculations using a plane-wave basis set. Phys. Rev. B 54, 11169 (1996).

42 Blöchl, P. E. Projector augmented-wave method. Phys. Rev. B 50, 17953 (1994).

43 Kresse, G. \& Joubert, D. From ultrasoft pseudopotentials to the projector augmentedwave method. Phys. Rev. B 59, 1758 (1999).

44 Heyd, J., Scuseria, G. E. \& Ernzerhof, M. Hybrid functionals based on a screened Coulomb potential. J. Chem. Phys. 118, 8207 (2003)

45 Heyd, J., Scuseria, G. E. \& Ernzerhof, M. Erratum: "Hybrid functionals based on a screened Coulomb potential" [J. Chem. Phys.118, 8207 (2003)]. J. Chem. Phys 124 219906 (2006).

46 Henkelman, G. \& Jónsson, H. A dimer method for finding saddle points on high dimensional potential surfaces using only first derivatives. J. Chem. Phys. 111, 7010 (1999).

47 Freysoldt, C., Neugebauer, J. \& Van de Walle, C. G. Fully ab initio finite-size corrections for charged-defect supercell calculations. Phys. Rev. Lett. 102, 016402 (2009).

48 Noh, J.-Y., Kim, H. \& Kim, Y.-S. Stability and electronic structures of native defects in single-layer MoS 2 . Phys. Rev. B 89, 205417 (2014)

49 Kumagai, Y. \& Oba, F. Electrostatics-based finite-size corrections for first-principles point defect calculations. Phys. Rev. B 89, 195205 (2014).

50 Nomura, K., Kamiya, T., Ohta, H., Uruga, T., Hirano, M. \& Hosono, H. Local coordination structure and electronic structure of the large electron mobility amorphous oxide semiconductor In-Ga-Zn-O: experiment and ab initio calculations. Phys. Rev. B 75, 035212 (2007).

51 Nomura, K., Kamiya, T. \& Hosono, H. Effects of diffusion of hydrogen and oxygen on electrical properties of amorphous oxide semiconductor, In-Ga-Zn-O. ECS J. Solid State Sci. Technol 2, P5-P8 (2013).

52 Nomura, K., Kamiya, T., Yanagi, H., Ikenaga, E., Yang, K., Kobayashi, K., Hirano, M. \& Hosono, H. Subgap states in transparent amorphous oxide semiconductor, In-Ga-Zn-O, observed by bulk sensitive x-ray photoelectron spectroscopy. Appl. Phys. Lett. 92 202117 (2008).

53 Bruneval, F., Crocombette, J.-P., Gonze, X., Dorado, B., Torrent, M. \& Jollet, F. Consistent treatment of charged systems within periodic boundary conditions: the projector augmented-wave and pseudopotential methods revisited. Phys. Rev. B 89, 045116 (2014).

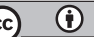

This work is licensed under a Creative Commons Attribution 4.0 International License. The images or other third party material in this article are included in the article's Creative Commons license, unless indicated otherwise in the credit line; if the material is not included under the Creative Commons license, users will need to obtain permission from the license holder to reproduce the material. To view a copy of this license, visit http:// creativecommons.org/licenses/by/4.0/ 